OPEN ACCESS

Edited by:

Claudia Cerella,

Fondation de Recherche Cancer et

Sang, Luxembourg

Reviewed by:

Gabriele Multhoff,

Technical University of Munich,

Germany

Duck Cho,

Sungkyunkwan University, South

Korea

*Correspondence:

Kaveh Baghaei

kavehbaghai@gmail.com

Javad Verdi

JavadOVerdi@gmail.com

Specialty section:

This article was submitted to Pharmacology of Anti-Cancer Drugs,

a section of the journal

Frontiers in Pharmacology

Received: 29 June 2021

Accepted: 12 August 2021

Published: 13 September 2021

Citation:

Abdolahi S, Ghazvinian Z, Muhammadnejad S, Ahmadvand M, Aghdaei HA, Ebrahimi-Barough S, Ai J, Zali MR, Verdi J and Baghaei K (2021) Adaptive NK Cell Therapy Modulated by Anti-PD-1 Antibody in Gastric

Cancer Model.

Front. Pharmacol. 12:733075.

doi: 10.3389/fphar.2021.733075

\section{Adaptive NK Cell Therapy Modulated by Anti-PD-1 Antibody in Gastric Cancer Model}

\author{
Shahrokh Abdolahi ${ }^{1}$, Zeinab Ghazvinian ${ }^{1}$, Samad Muhammadnejad ${ }^{2}$, \\ Mohammad Ahmadvand ${ }^{3,4}$, Hamid Asadzadeh Aghdaei ${ }^{5}$, Somayeh Ebrahimi-Barough ${ }^{6}$, \\ Jafar Ai ${ }^{6}$, Mohammad Reza Zali ${ }^{7}$, Javad Verdi ${ }^{1 *}$ and Kaveh Baghaei ${ }^{5,7 *}$ \\ ${ }^{1}$ Department of Applied Cell Sciences, School of Advanced Technologies in Medicine, Tehran University of Medical Sciences, \\ Tehran, Iran, ${ }^{2}$ Cell-Based Therapies Research Center, Digestive Diseases Research Institute, Tehran University of Medical \\ Sciences, Tehran, Iran, ${ }^{3}$ Hematology-Oncology and Stem Cell Transplantation Research Center, Tehran University of Medical \\ Science, Tehran, Iran, ${ }^{4}$ Department of Hematology and Applied Cell Sciences, Faculty of Medical Sciences, Tarbiat Modares \\ University, Tehran, Iran, ${ }^{5}$ Basic and Molecular Epidemiology of Gastrointestinal Disorders Research Center, Research Institute for \\ Gastroenterology and Liver Diseases, Shahid Beheshti University of Medical Sciences, Tehran, Iran, ${ }^{6}$ Department of Tissue \\ Engineering, School of Advanced Technologies in Medicine, Tehran University of Medical Sciences, Tehran, Iran, \\ ${ }^{7}$ Gastrointestinal Disorders Research Center, Research Institute for Gastroenterology and Liver Diseases, Shahid Beheshti \\ University of Medical Sciences, Tehran, Iran
}

Recently, adaptive NK cell therapy has become a promising treatment but has limited efficacy as a monotherapy. The identification of immune checkpoint inhibitor (ICl) molecules has opened a new horizon of immunotherapy. Herein, we aimed to demonstrate the cytotoxic effects of a polytherapy consisting of ex vivo expanded IL2-activated NK cells combined with human anti-PD-1 antibody as an important checkpoint molecule in a xenograft gastric cancer mouse model. EBV-LCL cell is used as a feeder to promote NK cell proliferation with a purity of 93.4\%. Mice (NOG, female, 6-8 weeks old) with xenograft gastric tumors were treated with PBS, ex vivo IL-2-activated NK cells, IL-2activated NK cell along with human anti-PD-1 (Nivolumab), and IL-2-activated pretreated NK cells with anti-PD-1 antibody. The cytotoxicity of ex vivo expanded NK cells against $\mathrm{MKN}-45$ cells was assessed by a lactate dehydrogenase $(\mathrm{LDH})$ assay. Tumor volume was evaluated for morphometric properties, and tumor-infiltrating NK cells were assessed by immunohistochemistry $(\mathrm{IHC})$ and quantified by flow cytometry. Pathologic responses were considered by $\mathrm{H}$ and $\mathrm{E}$ staining. Ex vivo LDH evaluation showed the cytotoxic potential of treated NK cells against gastric cancer cell line. We indicated that the adoptive transfer of ex vivo IL-2-activated NK cells combined with anti-PD-1 resulted in tumor growth inhibition in a xenograft gastric cancer model. Mitotic count was significantly decreased ( $\left.{ }^{*} p<0.05\right)$, and the tumor was associated with improved infiltration of NK cells in the NK-anti-PD-1 pretreated group ( $\left.{ }^{*} p<0.05\right)$. In conclusion, the combination approach of activated NK cells and anti-PD-1 therapy results in tumor growth inhibition, accompanied by tumor immune cell infiltration in the gastric tumor model.

Keywords: anti-PD-1 antibody, NK cell therapy, immune checkpoint inhibitor, immunotherapy, gastric cancer 


\section{INTRODUCTION}

Gastric cancer (GC) is the fifth leading cause of cancer and the third leading cause of death. (Thrift and El-Serag 2020). GC has low clinical symptoms, and it usually progresses at the time of diagnosis, making it challenging to treat patients. Various treatments can be considered, including surgery, chemotherapy, radiation therapy, and targeted therapies (Meza-Junco, Au et al., 2011; Wadhwa, Taketa et al., 2013). However, even after conventional treatments, many patients experience a recurrence of the disease and eventually, cancer metastasizes to other tissues (Enzinger and Mayer 2003). Therefore, consideration of innovative therapeutic approaches is of great importance. Indeed, there is an increasing investigation in establishing an effective immune cell-based therapy for GC by ex vivo activating and expanding immune cells. Multifarious studies have presented the therapeutic potential of effective immunotherapy of immune cells (Rezvani, Daher et al., 2020; Ingram, Madan et al., 2021).

Natural killer (NK) cells are promising approaches in treating solid tumors that recognize and lyse infected and malignant cells and exert their cytotoxicity effect without prior sensitization (Close 2016; Jung et al., 2018). NK cells are stimulated as anticancer agents by downregulating or lost MHC-I molecules, a process in which tumor cells can usually escape from cytotoxic T lymphocytes (CTLs) recognition (van Erp, van Kampen et al., 2019). Furthermore, NK cells activation is related to the balance between activating and inhibitor receptors and independent of antigen-presenting cells (APC) (Ljunggren and Malmberg 2007). Despite the advantages of NK therapy, there are major challenges in tumor infiltration or tumor site suppression (Li, Zhang et al., 2016; Melaiu, Lucarini et al., 2020). In an immunological response context, a tumor without infiltrating lymphocytes (TILs) is defined as a "noninflamed" or "cold" tumor (Herbst, Soria et al., 2014; Mlecnik, Bindea et al., 2016). In contrast, "hot" tumors show a high number of TILs, making the TME more responsive to immunotherapeutic interventions (Kitano, Ono et al., 2017).

There are reasons for the tumor site suppression of adaptive NK cell monotherapy, including (i) myeloid-derived suppressor cells (MDSCs) and Tregs function (Pedroza-Pacheco, Shah et al., 2016; Liu, Wei et al., 2018); (ii) overexpression of MHC class I and MICA/B (Malmberg, Carlsten et al., 2017; Raneros, Puras et al., 2017); (iii) the expression level changes in activating and inhibitory receptors of NK cells (Pietra, Manzini et al., 2012; Davis, Vallera et al., 2017); (iv) marginal infiltration of NK cells (Uong, Lee et al., 2018). Therefore, any approaches to increase the efficacy of NK therapy should address the mentioned limitation. Among them, immune checkpoint inhibitors (ICI) have a crucial role in the cytotoxicity of NK cells.

PD-1 is a surface receptor known as an immunological checkpoint inhibitor for immune cells such as myeloid cells, thymocytes, activated T cells, and NK cells (Nishimura and Honjo 2001; Cheng, Veverka et al., 2013). PD-L1/2 ligands are expressed by various tumor cells, including liver cancer, breast, and GC (Engel, Honig et al., 2014; Jung, Jeong et al., 2017; Wu, Cao et al., 2017). By binding to its ligands, PD-1 plays a vital role in immunosuppressing by exhausting immune cells, increasing Tregs, reducing autoimmunity, and promoting tolerance (Keir,
Butte et al., 2008; Francisco, Sage et al., 2010; Fife and Pauken 2011). Thus, blocking this inhibitory pathway is a promising approach to increase the efficacy of cancer immunotherapy (Topalian, Drake et al., 2012). These therapies can be welltolerated compared with chemotherapy and provide long-term survival (Chiossone, Vienne et al., 2017). In addition, the PD-1 receptor can be targeted by a fully humanized IgG4 antibody (Nivolumab) and can attenuate the inhibitory signal of NK and T, responding to treatment in highly immunogenic tumors ( $\mathrm{Li}$, Shao et al., 2018; Havel, Chowell et al., 2019; Desai, Deva et al., 2020).

There have been limited studies on adaptive NK therapy on GC; however, it has been demonstrated that the infiltration and cytotoxicity effects of NK are major problems (Chen, Yang et al., 2014; Du and Wei 2019). Therefore, in the current study, to overcome the limitations, we surveyed the combination therapy of activated NK cells with Nivolumab as an anti-PD-1 inhibitor to enhance tumor infiltration and cytotoxicity of NK against gastric cancer tumors.

\section{MATERIALS AND METHODS}

\section{Cell Lines and Culture Media}

The MKN-45 cell line (human gastric cancer cell line) was purchased from the Iranian Biological Resource Center (Tehran, Iran). Epstein-Barr virus (EBV)-transformed lymphoblastoid cell line (LCL) as feeder cells was maintained in Roswell Park Memorial Institute-1640 (RPMI-1640) (Gibco, United States); media were supplemented with 10\% FBS (Gibco, United States), $1 \%$ penicillin-streptomycin, and 1\% L-glutamine.

\section{Human NK Cell Isolation, Ex Vivo Expansion, and Activation}

NK cells were isolated from healthy donors' buffy coats with Ficoll Paque Premium (GE Healthcare's, United States) gradient centrifugation. According to the manufacturer's instructions, NK cells were collected by negative selection using a human NK cell isolation kit (Miltenyi Biotech, Germany). The purity of NK cells was assessed by flow cytometry analysis of $\mathrm{CD}^{-}$and $\mathrm{CD}^{-} 6^{+}$markers (FACSCalibur Becton Dickinson, United States). EBV-LCL was applied for optimal NK cell expansion. EBV-LCL cell line was established by culturing peripheral blood mononuclear cells (PBMCs) in the presence of $100 \mu \mathrm{g} / \mathrm{ml}$ cyclosporin A with EBV supernatant harvested from the cell line B95-8 (Iranian Biological Research Center) (Igarashi, Wynberg et al., 2004). The procedure is based on an existing expansion protocol for in vivo studies (Berg, Lundqvist et al., 2009) that utilizes 100 Gy-irradiated EBV-LCL as feeder cells (at a ratio of 1:10) trigger NK cell proliferation and highly activated NK cells. In the first 5 days, NK cell colonies are formed, and every 3 days, a fresh medium enriched by IL-2 (500 IU/ml) (Miltenyi Biotech, Germany) is added to the cells for 21 days.

\section{Cytotoxicity Assays}

The cytotoxic effects of activated NK cells as an effector cell (E), whether alone and in combination with anti-PD-1, were defined in a co-culture of MKN-45 as a target cell (T). The ratios of 1:1, 1: 


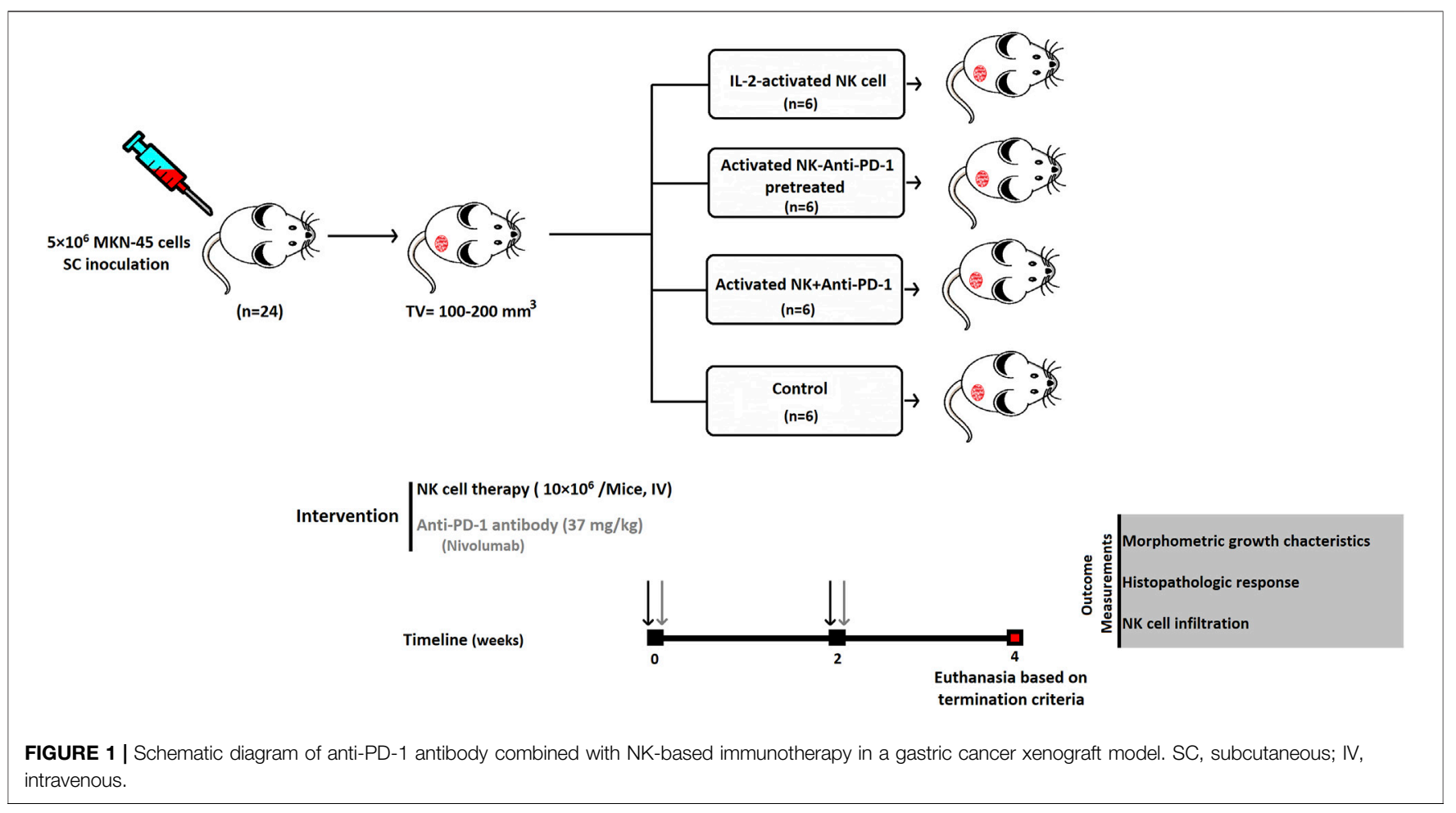

3, and 1:6 were studied. LDH assay was performed after $24 \mathrm{~h}$ of incubation as a necrosis marker in a cell culture medium (Chan, Moriwaki et al., 2013).

\section{Heterotopic Gastric Cancer Mouse Model}

All animals were housed in individually ventilated cages (IVC) for animal experiments. The center maintains standardized housing conditions and hygiene management according to the guidelines of the ethics committee. The animals are preserved under special conditions, e.g., a 12/12 h light-dark cycle, a humidity of $65 \%$, and a temperature of $25^{\circ} \mathrm{C}$. To assess the antitumor effect of NK cells in combination with Nivolumab (Bristol Myers Squibb, USA) in vivo, we used 6-8-week-old female NOD. Cg-Prkdcscid IL2rgtm1Sug (NOG) mice were obtained from the animal facility of the Digestive Disease Research Institute of Tehran University of Medical Sciences, which subcutaneously inoculated by $5 \times 10^{6} \mathrm{MKN}-$ 45 cells. Prior to euthanasia, animals are anesthetized with ketamine and xylazine and euthanized with $\mathrm{CO}_{2}$. Tumor sizes and body weights were measured twice a week. Animals with a tumor volume $\geq 2000 \mathrm{~mm}^{3}$, real bodyweight loss $\geq 20 \%$, or BC $=1$ (body condition) were humanely terminated. All animal experiments were authorized by the institutional ethics committee of the Tehran University of Medical Science (IR.TUMS.MEDICINE.REC.1399.644).

\section{Sample Size, Dosages, and Schedule of Administration}

Tumor median size of $100-200 \mathrm{~mm}^{3}$ (day 0) was selected for dividing the animals randomly into four experimental groups, including IL-2-activated NK cells (NK cells), IL-2-activated NK cells along with anti-PD-1 antibody (Nivolumab) (NK + anti-PD-
1), and IL-2-activated NK cells ex vivo pretreated with $20 \mu \mathrm{g} / \mathrm{ml}$ anti-PD-1 (NK-anti-PD-1 pretreated). Each mouse received $10 \times 10^{6} \mathrm{NK}$ cells twice at 2 -week intervals via the IV route (Figure 1). The dosage of anti-PD-1 (Nivolumab) was translated from human into murine setting based on body surface area using the following formula (Nair and Jacob 2016):

$$
\begin{aligned}
& \text { Murine equivalent dosage (unit/kg) } \\
& =\text { pediatric dosage }(\text { unit } / \mathrm{kg}) \times \frac{\text { Human } \mathrm{Km}}{\text { Mouse } \mathrm{Km}} .
\end{aligned}
$$

The Km constant was 37 for adult humans 37 and 3 for mice (Reagan-Shaw et al., 2008). The NK + anti-PD-1 group was treated with $37 \mathrm{mg} / \mathrm{kg}$ anti-PD-1 antibody twice at 2-week intervals via the IV route. Control is the fourth group, which received phosphate-buffered saline (PBS).

\section{Tumor Morphometric Outcomes}

Tumor volume was measured by a caliper and calculated by the following formula: tumor volume $=1 / 2$ (length $\times$ width 2 ). Relative tumor volume (RTV) was evaluated for morphometric growth kinetics of the tumors by dividing tumor volume on a measured day to tumor volume on day 0 . Antitumor activity was presented by tumor growth inhibition (TGI) percentage using a formula by Tsukihara et al.: TGI $(\%)=[1-($ RTV of the treated group)/(RTV of the control group)] $\times 100(\%)$ (Tsukihara, Nakagawa et al., 2015).

\section{Flow Cytometry}

NK cells characterization by PE anti-human $\mathrm{CD}^{+} 6^{+}$and FITC anti-human $\mathrm{CD}^{-}$markers was quantitatively evaluated; the 
TABLE 1 | Residual tumor (R) classification.

$\begin{array}{ll}\text { Classification } & \text { The entire tumor is destroyed in response to treatment } \\ \text { R0 } & \begin{array}{l}\text { More than } 70 \% \text { of the tumor is destroyed in response to treatment, and fibrosis and diffuse apoptosis (within the tumor) are } \\ \text { observed } \\ \text { R1 }\end{array} \\ \text { R2 } & \begin{array}{l}30 \text { and } 70 \% \text { of tumors in response to treatment have undergone fibrosis and apoptosis } \\ \text { R3 }\end{array}\end{array}$

TABLE 2 | The Allred score combined intensity and percent of immunoreactive cells.

\begin{tabular}{|c|c|c|c|}
\hline Positive cells $\%$ & Proportion score & Intensity & Intensity score \\
\hline No cells are immunoreactive & 0 & Negative & 0 \\
\hline$\leq 1 \%$ & 1 & Weak & 1 \\
\hline $1-10 \%$ & 2 & Intermediate & 2 \\
\hline $11-33 \%$ & 3 & Strong & 3 \\
\hline $34-66 \%$ o & 4 & & \\
\hline $67-100 \%$ & 5 & & \\
\hline
\end{tabular}

Aggregation of proportion and Intensity score

$0-1$

$2-3$

$4-6$

$7-8$
Negative

Weak positive

Intermediate positive

High positive infiltration of NK cells at the tumor site was performed using flow cytometry (FACSCalibur Becton Dickinson, United States). NKG2D and CD69 were evaluated before and after treatment of IL-2-stimulated NK cells by the anti-PD-1 antibody for further characterization. The whole tumor was collected and digested mechanically and enzymatically, and staining was done according to the manufacturer's instructions; then, flow cytometry was performed (Feng, Peng et al., 2009). Data were analyzed using the FlowJo 7 software (Tree Star, Inc.). Experiments were carried out in triplicate and quantified by GraphPad Prism 9 (GraphPad Software Inc., CA, United States).

\section{Histopathology Assessments}

The histopathologic response of tumors to the interventions was assessed based on the residual tumor (R) (Edge, Byrd et al., 2010) (Table 1). Hematoxylin and Eosin (H and E) stain slides were prepared to stratify the histopathologic responses. Proliferative activity changes assessed mitotic count on $\mathrm{H}$ and $\mathrm{E}$ slides. As previously described by Meuten and colleagues, mitotic cells are counted in areas and reported as an average over ten consecutive high power fields (HPF) (Meuten, Moore et al., 2016).

Immunohistochemistry (IHC) against human CD56 (Biolegend, United States) was performed as described previously (Kim et al., 2016) for NK cell infiltration evaluation. Furthermore, the active protein of caspase 3 for apoptosis induction evaluation was detected using a rabbit polyclonal antibody (Biolegend, United States). IHC was assessed based on the Allred score; this scoring combines the percentage of immunoreactive cells and the intensity score (Parvin et al., 2019) (Table 2). Following the euthanasia of the mice, tumor tissues were collected and processed for paraffin embedding. Briefly, paraffin-embedded tumors were cut by microtome to a thickness of $4 \mu \mathrm{m}$. After deparaffinization and hydration, the tumor tissues were incubated by primary and secondary antibodies (Adan, Alizada et al., 2017).

\section{Statistical Analysis}

All results are reported as the mean \pm SEM and the data were analyzed by GraphPad Prism 9 software package (GraphPad Software, Inc., San Diego, United States). A $p$ value of $<0.05$ represented statistical significance.

\section{RESULTS}

\section{Ex Vivo Expansion and Immunophenotyping of NK Cells}

NK cells isolated from peripheral blood were characterized by the presence of CD56 and the absence of CD3 as NK cell surface biomarkers. The purity was $93.4 \%$, which included the $\mathrm{CD}^{-}$ $\mathrm{CD}_{56}{ }^{+}$cells based on flow cytometric analysis. Freshly isolated CD3 - and CD56+ cells were cultured in the presence of IL-2 and feeder cells and expanded for 21 days. Expanded NK cells exhibited clonal growth and round shape morphology under cytokine-/feeder-enriched (IL-2/EBV-LCL cells) medium; finally, after 21 days, we reached 370 million cells with more than $95 \%$ viability, which were evaluated by trypan blue before injection (Figures 2A,B). 

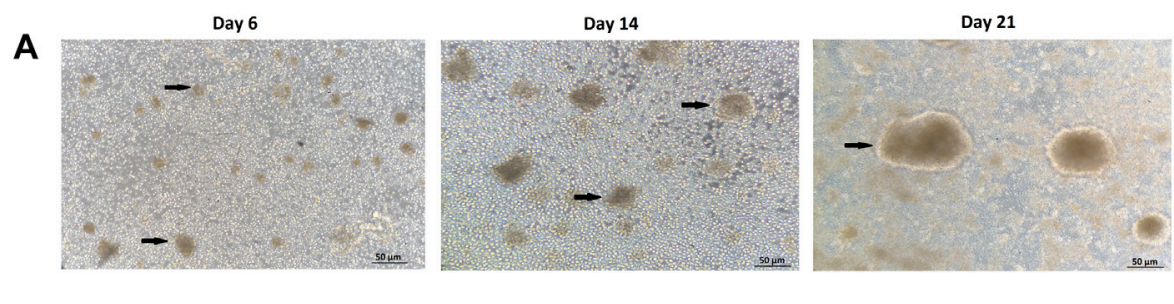
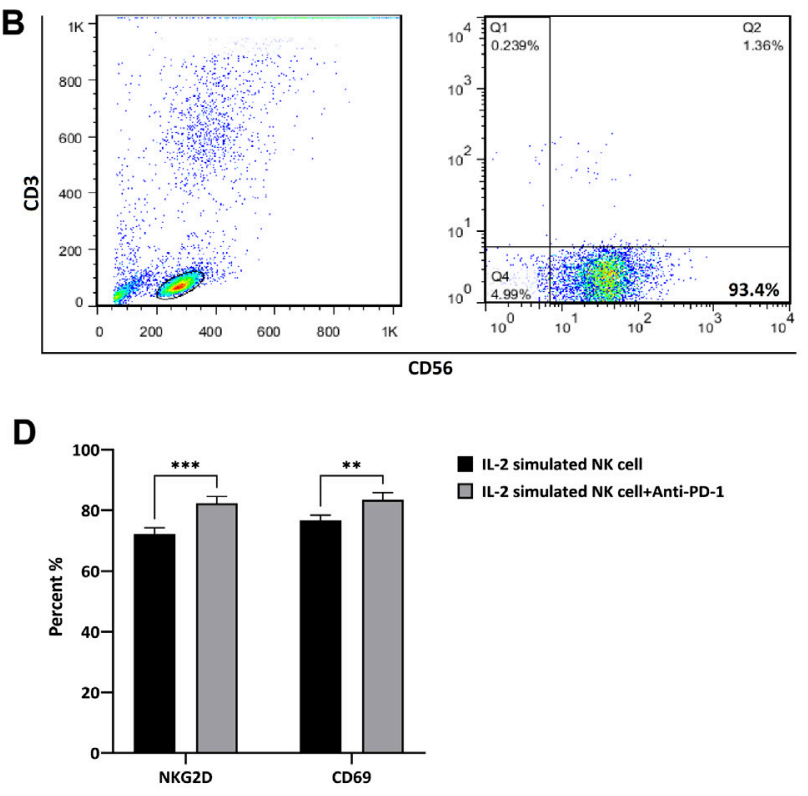
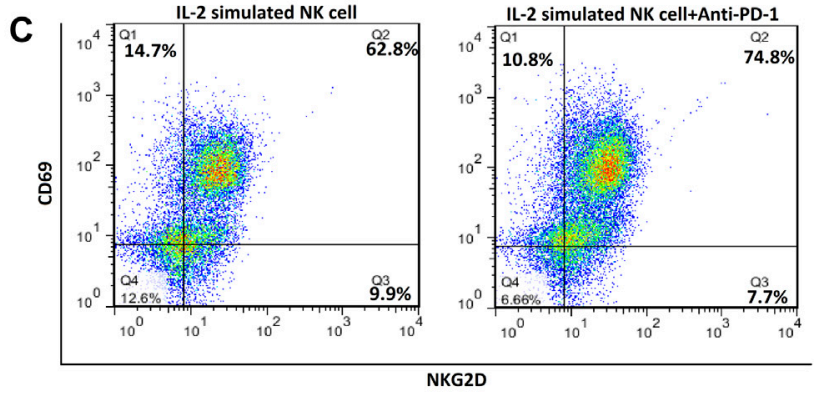

E

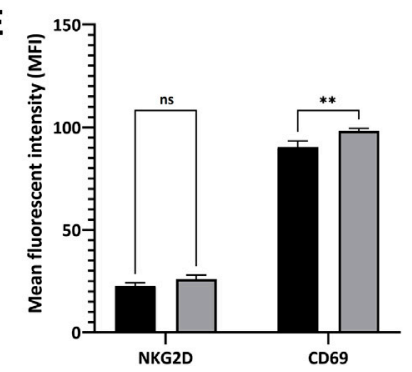

FIGURE 2 | Isolation, characterization, and expansion of NK cells. (A) The morphology of NK cells after 6, 14, and 21 days of round-shaped colony of NK cells is illustrated by arrows. (B) The frequency of CD56+CD3-NK cells in PBMC-derived NK cells, after MACS isolation with more than 93.4\% purity. (C) The frequency of NKG2D and CD69 marker before and after treatment of IL-2-stimulated NK cells by anti-PD-1 antibody. (D) The quantification of positive cells for NKG2D and CD69 marker. (E) The quantification of mean fluorescence intensity for NKG2D and CD69 marker. Data presented as means \pm standard error ( $\mathrm{M} \pm \mathrm{SE}$ ) for three independent experiments. Statistical significance was determined using one-way ANOVA with * $p<0.05$. Scale bar: 50 um, magnification $200 X$. ns, not significant.

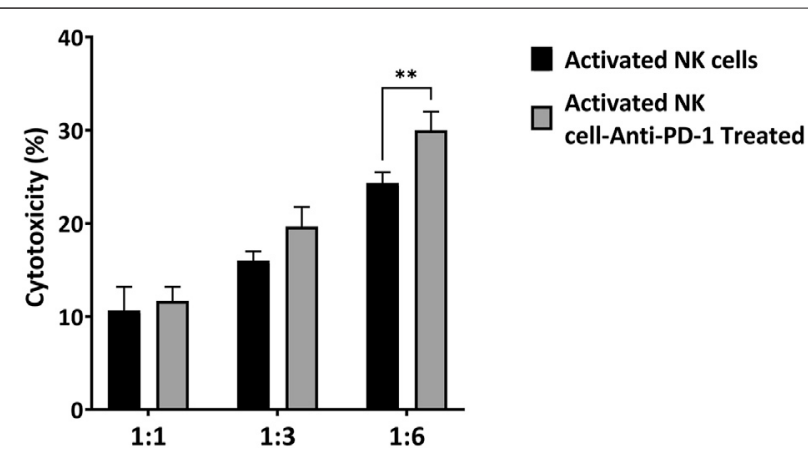

FIGURE 3 | Cytotoxicity of ex vivo activated NK cells and anti-PD1 antibody-treated NK cells toward MKN-45 cell at different E: T ratios. Data presented as means \pm standard error $(\mathrm{M} \pm \mathrm{SE})$ for three independent experiments. Statistical significance was determined using one-way ANOVA with ${ }^{*} p<0.05$.

Further investigation of NK + anti-PD-1 immunophenotyping NKG2D and CD69 was performed using flow cytometry. NK $\mathrm{NKG}_{2} \mathrm{D}^{+}$and $\mathrm{CD}^{+} 9^{+}$cells increased 10 and 8 percent after treatment with IL-2-stimulated NK cells with anti-PD-1 antibody ( $p<0.0007$ and $p<0.0085$, respectively). Moreover, quantification of mean fluorescence intensity (MFI) showed that anti-PD-1 treatment improved CD69 expression $(p<0.002)$, but no significant changes were observed in NKG2D marker after treatment with IL-2stimulated NK cells with anti-PD-1 (Figures 2C,D,E).

\section{Ex Vivo Cytotoxicity of IL-2-Activated NK Cells Combined With Anti-PD-1}

To evaluate the effect of a combined strategy of IL-2-activated NK cells with anti-PD-1 antibody in vitro, MKN-45 cells were cocultured with activated NK cells at three specific E: T ratios (1:1, 3:1, and 6:1). After a $24 \mathrm{~h}$ incubation, the NK-cell-mediated cytotoxicity against MKN-45 was detected by LDH assay. In the non-treated group, NK cells showed 11, 16, and 25 percent cytotoxicity at the following $\mathrm{E}: \mathrm{T}$ ratios: $1: 1,3: 1$, and $6: 1$, respectively. In the anti-PD-1-treated group, the lysis percentages were 13,19 , and 30 . The most prominent antitumor cytotoxicity of activated NK cells was achieved when PD-1 was inhibited with an anti-PD-1 antibody $(p<0.006)$ (Figure 3). 

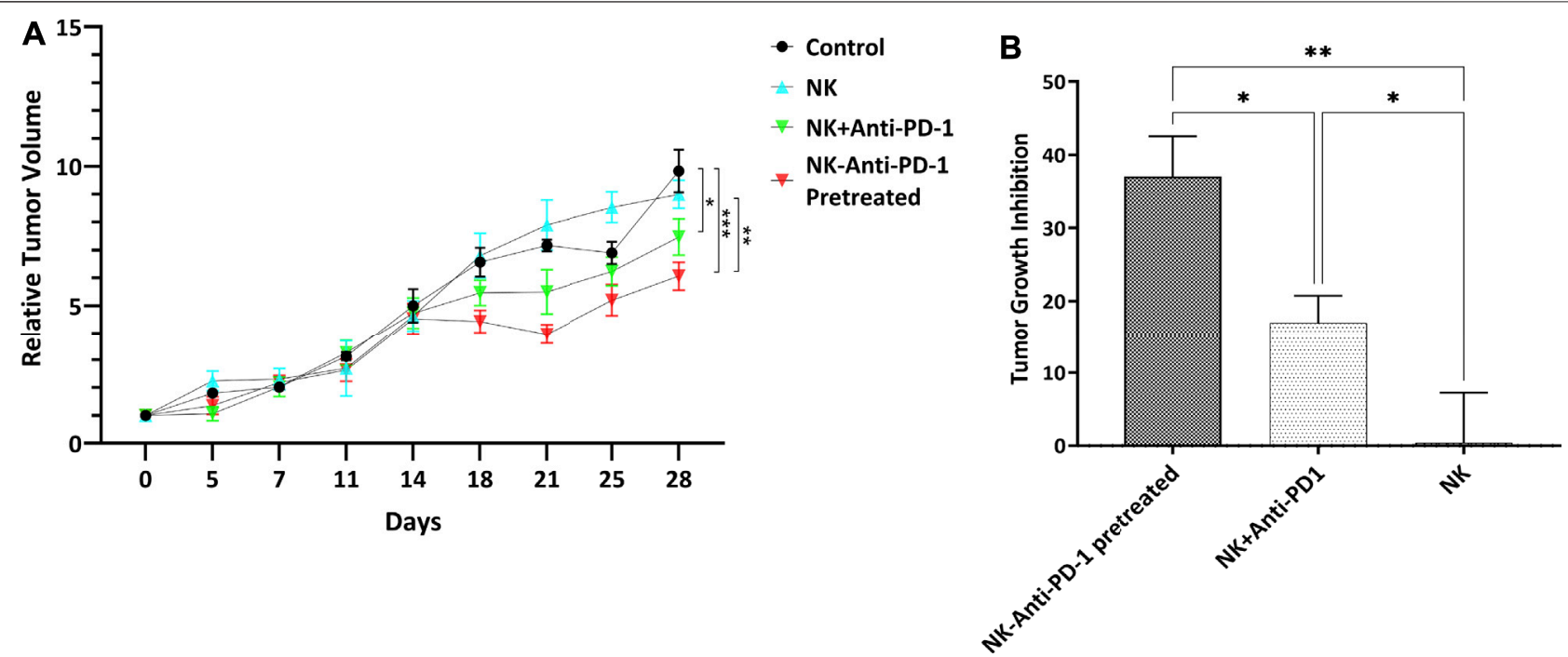

FIGURE 4 | Morphometric growth characteristics. (A) RTV versus the elapsed time curve showed tumor growth variations. (B) Tumor growth inhibition of interventions normalized with control tumor. Data presented as means \pm standard error $\left(\mathrm{M} \pm \mathrm{SE}\right.$ ). Statistical significance was determined using 2-way ANOVA with ${ }^{*} p<0.05$.

\section{The Therapeutic Effect of NK Cells Based on Morphometric Growth Characteristics in Gastric Cancer Xenograft Model}

In order to explore the effect of adaptive NK cell therapy combined with Nivolumab in tumor growth in vivo, we further investigated the impact of interventions on the morphometric properties in the subcutaneous transplantation mouse model of gastric cancer using MKN-45 cell line.

The use of an Anti-PD-1 antibody confirms the hypothesis that PD-1/PDL-1 pathway inhibition can modulate the therapeutic cytotoxicity effect of NK cells. Ten days after cell line inoculation, tumors reached the desired size of $100-200 \mathrm{~mm}^{3}$ for interventions. The sham-treated mice showed the most rapid tumor growth. Two IV injections of ex vivo IL-2-activated NK cells combined with an antiPD-1 antibody caused a significant tumor growth delay. The morphometric growth curves of tumors are shown in Figure 4A. Optimal percent of TGI was observed 28 days after the beginning of treatment. The highest tumor growth inhibition was considered in the NK-anti-PD-1 pretreated group, with a median TGI of 38\% (31-41). Also, the NK + anti-PD-1 therapy group showed an inhibitory effect with a median TGI of $18 \%$ (12-19); NK cells as monotherapy did not show an inhibitory effect on the gastric cancer model with a median TGI of $-0.5 \%$. NK-anti-PD-1 pretreated group significantly inhibited tumor growth more than NK + anti-PD-1 and NK cells $(p<0.01$ and $p<0.001$, respectively). Furthermore, NK + anti-PD-1 induces tumor inhibition compared to NK cells $(p<0.03)$. The best therapeutic outcome was observed after modulating NK cells by anti-PD-1 antibody (Figure 4B).

\section{Effects of Experimental Interventions on Histopathologic Outcomes}

PD-1 blockade was used to improve response to the immune-cellbased therapy approach. After implantation of $5 \times 10^{6} \mathrm{MKN}-45$ cells, the mice bearing tumor was intravenously injected with $10 \times 10^{6} \mathrm{NK}$ cells, NK-anti-PD- 1 pretreated, NK + anti-PD- 1 , and PBS (control).

NK-anti-PD-1 pretreated group based on residual tumor showed that in more than $30 \%$ of tumors, the fibrosis areas and apoptotic fragment were increased, R2 histologic response $(p<0.0001)$, in response to intervention. Furthermore, the NK + anti-PD-1 group showed a low response rate, R3 histologic response $(p<0.02)$. NK cells showed a degree of histopathologic response, which not statistically significant (Figures 5A,B).

Mitotic count was investigated to evaluate the effect of interventions on tumor proliferation intensity. NK cells antiPD-1 pretreated showed the highest anti-proliferative effect; the mitotic count in this group was significantly lower than that in the control group $(12[8-15]$ vs. $21.5[19-35](p<0.002)$. Furthermore, the mitotic count of the NK + anti-PD-1 group was significantly decreased compared to the control 14 [9-21] $(p<0.03)$, but NK cells did not show a difference in mitotic count (Figure 5C).

The cytotoxicity mechanism of different treated groups via apoptosis was evaluated by caspase 3 labeling. Our findings based on Allred score show that NK cells-anti-PD-1 pretreated and NKAnti-PD-1 groups have intermediate level of caspase 3, while NK cell alone was weakly positive for caspase 3 (Figure 6).

\section{In Vivo Treatment of NK-Anti-PD-1 Increased Lymphocyte Infiltration}

In order to verify the NK cell permeation, human $\mathrm{CD}^{+} 6^{+}$cells were evaluated. NK-anti-PD-1 pretreated cells were intermediate positive and the other treated groups that received NK cells were weakly positive for CD56 biomarker based on Allred score (Figure 7A). The infiltration percentage of the NK cells, NK + 


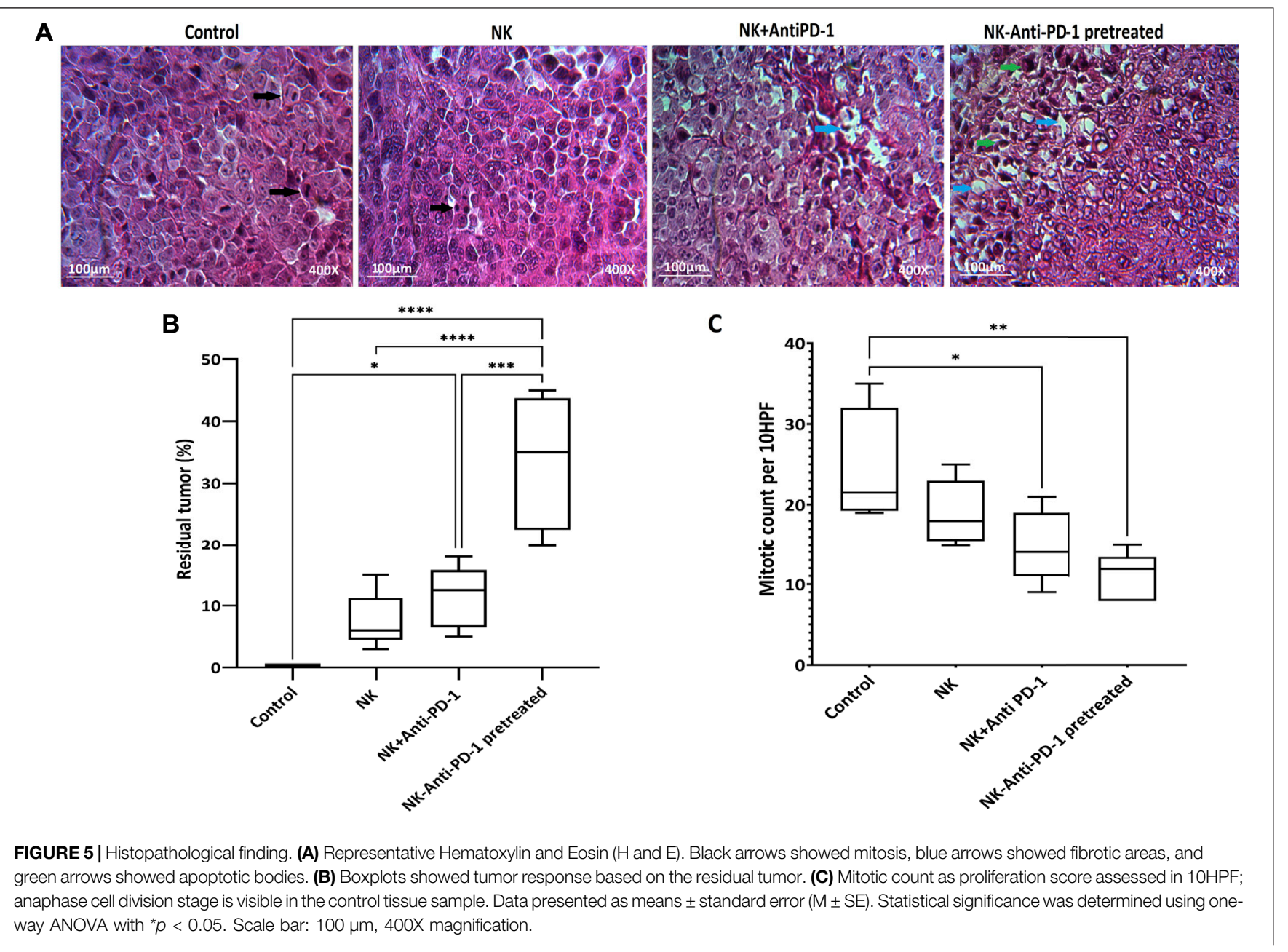

anti-PD-1, and NK-anti-PD-1 pretreated cells groups were 3, 5, and $7 \%$, respectively. Thus, this result indicated that NK-anti-PD1 pretreated group showed the highest infiltration $(p<0.008)$ (Figure 7B).

\section{DISCUSSION}

The low number and infiltration of NK cells in the tumor area are challenging in GC patients (Li, Zhang et al., 2016; Peng, Zhang et al., 2017). PD-1 receptor as ICIs molecules negatively regulates $\mathrm{T}$ and NK cells. Therefore, GC tumors using PD-1 receptors inhibit the patient 's immune system. (Lesokhin, Callahan et al., 2015; Liu, Cheng et al., 2017). Accordingly, PD-1 inhibitor has been shown to enhance immunity in clinical trials of non-small cell lung cancer (NSCLC), colorectal cancer, gastric cancer, head, and neck squamous cell carcinoma (Brahmer, Rodríguez-Abreu et al., 2017; Kang, Boku et al., 2017; Overman, McDermott et al., 2017; Tahara, Muro et al., 2018). Recent advances in combination therapy targeting tumor microenvironment or immune checkpoint molecules seem advantageous for NK cell therapy.

In this study, anti-PD-1 antibodies were combined with NK cell-based therapy in gastric cancer xenograft mouse models. As reported in previous studies, a blockade of immune checkpoints can increase the efficiency of NK cell therapy by increasing cytotoxic activity. Bo Yuan Huang et al. and Shevtsov et al. (2019) have shown that PD-1 inhibited the increase in cytotoxic potency of NK cells by up to $10 \%$ (Huang, Zhan et al., 2015; Shevtsov, Pitkin et al., 2019). While the present study indicated ex vivo expanded IL-2-activated NK cells have therapeutic cytotoxic potential toward MKN-45 cells in vitro, anti-PD-1-treated IL-2-activated NK cells improved cytotoxicity of NK cells by $5 \%$.

It has been confirmed that the mechanism underlying tumor recognition by NK cells was mainly through human lymphoid stress surveillance. These cells recognize and kill the cells that express NKG2D ligands (Shafi, Vantourout et al., 2011). NKG2D ligands were downregulated on normal tissues, whereas they were upregulated on the malignant cells (Groh, Bahram et al., 1996). Furthermore, the crucial role of NKG2D-mediated tumor surveillance is confirmed by the rapid elimination of the tumor cells that were transfected with NKG2D ligands by immune cells (Diefenbach, Jensen et al., 2001). In addition to NKG2D, the non-exclusive cytotoxic mechanism of NK cells and other molecules like CD69 might be implicated as a proliferative and cytotoxic marker (Borrego, Robertson et al., 1999). Our 

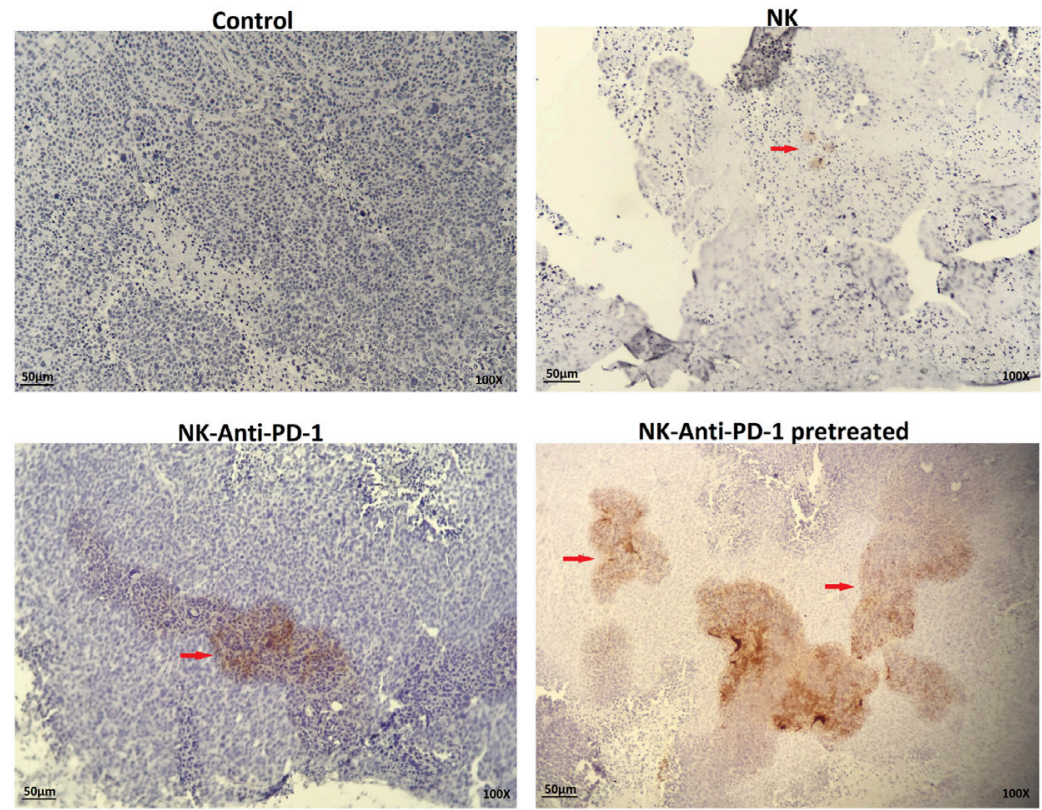

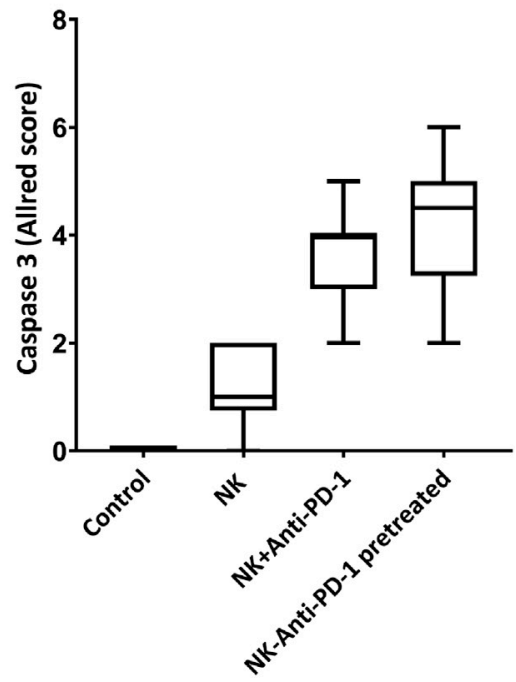

FIGURE 6 | Apoptosis induction by anti-PD-1 blockade NK cells. (A) Active caspase-3 was evaluated in the tumor section (red arrow, immunoreactive cells) and boxplots illustrate semi-quantitative analysis based on Allred score. Scale bar: $50 \mu \mathrm{m}, 100 \mathrm{X}$ magnification.

results indicated that anti-PD-1 blockade could promote an elevation of NKG2D and CD69 expression levels, and this increase could be modulated by immune-promoting molecules (Marçais, Viel et al., 2013). In confirmation of our results, Dai et al. have shown that anti-PD-1 antibody increases NKG2D and other cytotoxic factors (Dai, Lin et al., 2016), demonstrating the synergistic effect of these therapeutic approaches. Our proof-ofprinciple study has illustrated the promising results of a combination therapy of ex vivo expanded IL-2-activated NK cells and anti-PD-1 antibody. The therapeutic efficacy observed in this experiment is in line with the previously reported effects (Janjigian, Bendell et al., 2018; Patel and Minn 2018). Furthermore, Chen et al. have performed a gastrointestinal (GI) cancer meta-analysis, which showed low responsiveness to ICIs molecules (Chen, Zhang et al., 2019). Therefore, the different cytotoxic improvements in these studies may be due to the different response rates of gastric cancer cells and different E: $\mathrm{T}$ ratios in this study.

In vivo interventions started at the $100-200 \mathrm{~mm}^{3}$ of xenograft tumor volume, equivalent to the advanced stages of human tumors (Alley, Hollingshead et al., 2004). Combination groups improved TGI, leading to proliferative activity reduction linked to better survival rates and increasing apoptotic bodies and fibrotic areas. In accordance with the tumor mitotic counts and apoptosis results, the level of caspase 3 in NK-anti-PD-1 pretreated group was highly increased. Moreover, Yin et al. and Oyer et al. have indicated that cytotoxicity and antitumor efficacy of NK cells recovered when combined with anti-PD-1/PD-L1 blockade (Oyer, Gitto et al., 2018; Yin, Di et al., 2018). On the other hand, $\mathrm{J} \mathrm{Li}$ et al. have shown that the knockdown of PD-L1 in human gastric cancer cells significantly improved the cytotoxic sensitivity to CIK (cytokine-induced killer cells) therapy (Li,
Chen et al., 2017). These results showed that a combination strategy might be an effective and promising approach for GC immunotherapy.

Antitumor responses in immunodeficient mice were accompanied by an infiltration of the tumors; when PD-1 blockade was used, more infiltration induction was observed than that in the other groups. Although NK cell or PD-1 blockade therapies individually elicit an antitumor response, combination therapy is significantly more effective. Konrad Kokowski et al. have shown that the combination of NK cell transfer and radiochemotherapy with second-line PD-1 inhibition improved the overall survival of a patient with NSCLC stage IIIb and induced a massive NKG2D + immune cell infiltration (Kokowski, Stangl et al., 2019). The effect of the anti-PD-1 antibody on lymphocytes expressing the PD-1 receptor can cause this synergistic effect. This combination strategy also showed high NK cell infiltration in preclinical models of lung cancer and glioblastoma (Shevtsov, Pitkin et al., 2019). The moderate response obtained to the combined strategy in vitro compared to in vivo is probably due to differences in PD-1/PDL-1 expression and other stimuli of this ligand and receptor in 2- and 3-dimensional environments (Terme, Ullrich et al., 2011; Jung 2014; Abiko, Matsumura et al., 2015). Moreover, the mild antitumor effect achieved by monotherapy of NK cells resulted in a delayed tumor progression, which was not significant, that probably required continued therapy at higher doses.

In our study, we used the PD-1 inhibitor for improving adaptive NK cell therapy. However, other ICIs (e.g., antiLAG3/PD-1, anti-NKG2A, anti-TIM-3 antibodies) have been reported to regulate antitumor functions of NK cells and thereby elevate their cytotoxic activity (André, Denis et al., 2018; Lanuza, Pesini et al., 2020; Zhang, Jiang et al., 2020). Thus, the 

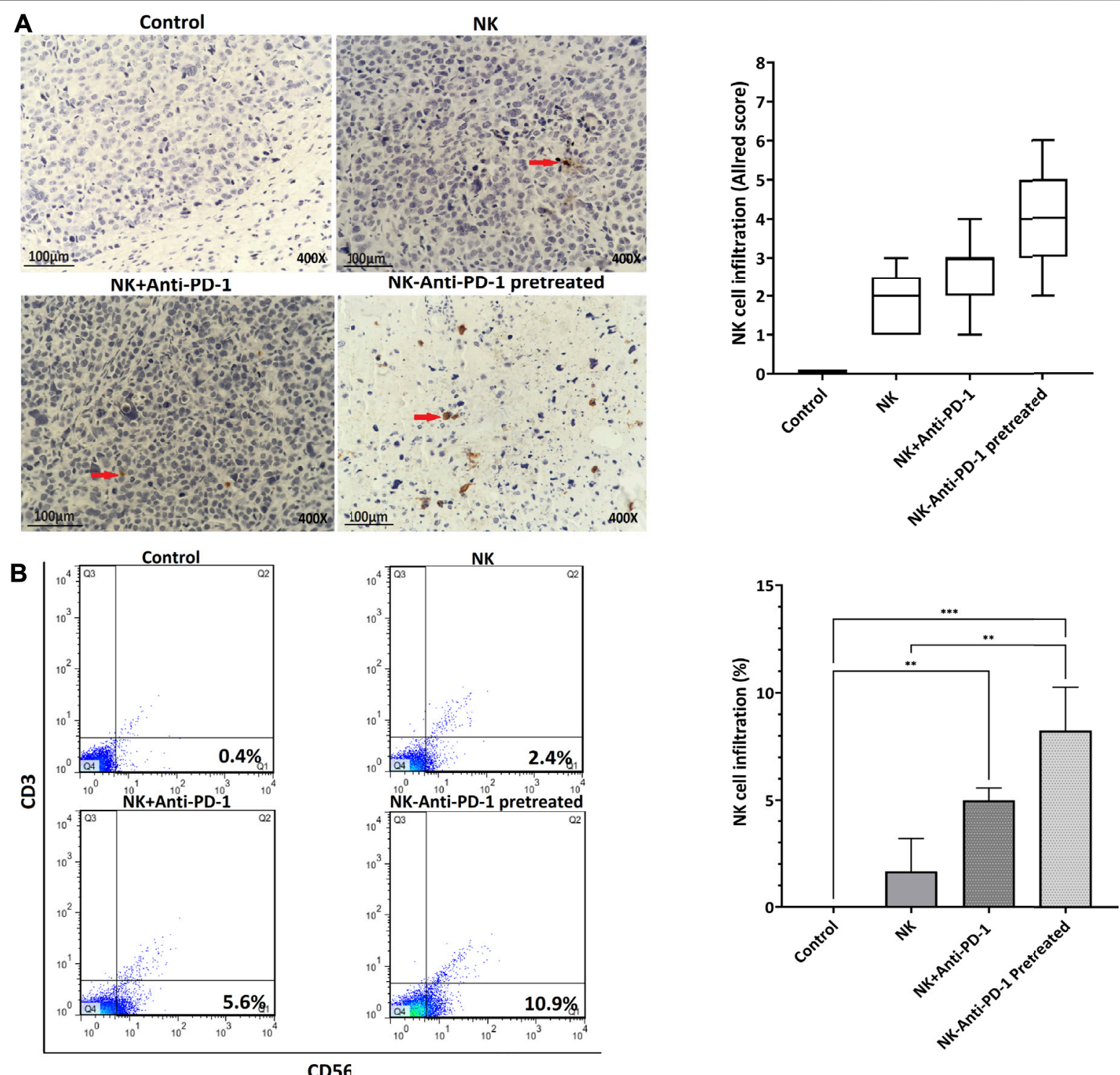

FIGURE 7 | In vivo treatment of NK cells increased lymphocyte infiltration. (A) Tumor microenvironment infiltrating NK cells were evaluated by IHC with anti-CD56 antibody in tumor masses (red arrow showed immunoreactive cells) and boxplots indicated semi-quantitative analysis based on Allred score. (B) Quantification of lymphocyte infiltration performed by whole tumor flow cytometry with anti-CD56 and anti-CD3 antibody, CD56+and CD3-cells showed infiltrating NK cells. Data presented as means \pm standard error $(M \pm S E)$ for three independent experiments. Statistical significance was determined using one-way ANOVA with ${ }^{*} p<0.05$. Scale bar: $100 \mu \mathrm{m}, 400 \mathrm{X}$ magnification.

combination therapy approach of IL-2-activated NK cells with several therapeutic antibodies can decrease exhaustion and enhance the cytotoxicity of NK cell-based immunotherapies.

The use of PD-1 blockade can cause other lymphocytes to accumulate in tumor sites such as cytotoxic T cells; NOG mice do not have immune cells (Shultz, Lyons et al., 2005). Therefore, the presence of other immune cells could not be assessed. However, the absence of an immune system confirms the antitumor function of NK cells, specifically with PD-1 blockade. Furthermore, a better clinical response is presumably observed in the presence of a complete immune system in clinical trials from this therapeutic approach.

\section{CONCLUSION}

Our results demonstrate the highest response of the combined strategy of NK and anti-PD1 in high T: E in vitro, and anti-PD-1 treatment improved proliferation and cytotoxic properties of NK cells. Furthermore, adaptive NK cells therapy with low efficacy in the monotherapy approach could be improved by adding an antiPD-1 antibody, and the pretreated strategy was more effective against the gastric cancer animal model. Therefore, the combination approach of ex vivo expanded IL-2-activated NK cell and PD- 1 blockade is promising, and its effectiveness could be evaluated in randomized clinical trials for gastric cancer. 


\section{DATA AVAILABILITY STATEMENT}

The original contributions presented in the study are included in the article/supplementary material; further inquiries can be directed to the corresponding author/s.

\section{ETHICS STATEMENT}

The animal study was reviewed and approved by the Tehran University of Medical Science.

\section{REFERENCES}

Abiko, K., Matsumura, N., Hamanishi, J., Horikawa, N., Murakami, R., Yamaguchi, K., et al. (2015). IFN- $\gamma$ from Lymphocytes Induces PD-L1 Expression and Promotes Progression of Ovarian Cancer. Br. J. Cancer 112 (9), 1501-1509. doi:10.1038/bjc.2015.101

Adan, A., Alizada, G., Kiraz, Y., Baran, Y., and Nalbant, A. (2017). Flow Cytometry: Basic Principles and Applications. Crit. Rev. Biotechnol. 37 (2), 163-176. doi:10.3109/07388551.2015.1128876

Alley, M. C., Hollingshead, M. G., Dykes, D. J., and Waud, W. R. (2004). "Human Tumor Xenograft Models in NCI Drug Development,” in Anticancer Drug Development Guide (Springer), 125-152. doi:10.1007/978-1-59259-739-0_7

André, P., Denis, C., Soulas, C., Bourbon-Caillet, C., Lopez, J., Arnoux, T., et al. (2018). Anti-NKG2A mAb Is a Checkpoint Inhibitor that Promotes Antitumor Immunity by Unleashing Both T and NK Cells. Cell 175 (7), 1731-e13. e1713. doi:10.1016/j.cell.2018.10.014

Berg, M., Lundqvist, A., McCoy, P., Jr, Samsel, L., Fan, Y., Tawab, A., et al. (2009). Clinical-grade Ex Vivo-expanded Human Natural Killer Cells Up-Regulate Activating Receptors and Death Receptor Ligands and Have Enhanced Cytolytic Activity against Tumor Cells. Cytotherapy 11 (3), 341-355. doi:10.1080/14653240902807034

Borrego, F., Robertson, M. J., Ritz, J., Peña, J. R., and Solana, R. (1999). CD69 Is a Stimulatory Receptor for Natural Killer Cell and its Cytotoxic Effect Is Blocked by CD94 Inhibitory Receptor. Immunology 97 (1), 159-165. doi:10.1046/j.13652567.1999.00738.x

Brahmer, J. R., Rodríguez-Abreu, D., Robinson, A. G., Hui, R., Csőszi, T., Fülöp, A., et al. (2017). Health-related Quality-Of-Life Results for Pembrolizumab versus Chemotherapy in Advanced, PD-L1-Positive NSCLC (KEYNOTE-024): a Multicentre, International, Randomised, Open-Label Phase 3 Trial. Lancet Oncol. 18 (12), 1600-1609. doi:10.1016/S1470-2045(17)30690-3

Chan, F. K.-M., Moriwaki, K., and De Rosa, M. J. (2013). "Detection of Necrosis by Release of Lactate Dehydrogenase Activity," in Immune Homeostasis (Springer), 65-70. doi:10.1007/978-1-62703-290-2_7

Chen, C., Zhang, F., Zhou, N., Gu, Y. M., Zhang, Y. T., He, Y. D., et al. (2019). Efficacy and Safety of Immune Checkpoint Inhibitors in Advanced Gastric or Gastroesophageal junction Cancer: a Systematic Review and Meta-Analysis. Oncoimmunology 8 (5), e1581547. doi:10.1080/ 2162402X.2019.1581547

Chen, J., Yang, J., Jiang, J., Zhuang, Y., and He, W. (2014). Function and Subsets of Dendritic Cells and Natural Killer Cells Were Decreased in Gastric Cancer. Int. J. Clin. Exp. Pathol. 7 (11), 8304-8311.

Cheng, X., Veverka, V., Radhakrishnan, A., Waters, L. C., Muskett, F. W., Morgan, S. H., et al. (2013). Structure and Interactions of the Human Programmed Cell Death 1 Receptor. J. Biol. Chem. 288 (17), 11771-11785. doi:10.1074/ jbc.M112.448126

Chiossone, L., Vienne, M., Kerdiles, Y. M., and Vivier, E. (2017). "Natural Killer Cell Immunotherapies against Cancer: Checkpoint Inhibitors and More," in Seminars in Immunology (Elsevier). doi:10.1016/j.smim.2017.08.003

Close, H. J. (2016). Immune Evasion in Glioma. Dissertation. (Leeds): University of Leeds.

Dai, C., Lin, F., Geng, R., Ge, X., Tang, W., Chang, J., et al. (2016). Implication of Combined PD-L1/pd-1 Blockade with Cytokine-Induced Killer Cells as a

\section{AUTHOR CONTRIBUTIONS}

S Abdolahi, S Muhammadnejad, and K Baghaei contributed to the study design. S Abdolahi, S Muhammadnejad, K Baghaei, and M Ahmadvand developed the methodology. S Muhammadnejad, $\mathrm{H}$ A Aghdaei, and J Verdi were responsible for providing the facility and animals. S Abdolahi, S Muhammadnejad, S E Barough, and J Ai analyzed and interpreted the data. S Abdolahi, J Verdi, S Muhammadnejad, and K Baghaei wrote and reviewed the manuscript. J Verdi and K Baghaei supervised the study.

Synergistic Immunotherapy for Gastrointestinal Cancer. Oncotarget 7 (9), 10332-10344. doi:10.18632/oncotarget.7243

Davis, Z. B., Vallera, D. A., Miller, J. S., and Felices, M. (2017). "Natural Killer Cells Unleashed: Checkpoint Receptor Blockade and BiKE/TriKE Utilization in NKMediated Anti-tumor Immunotherapy," in Seminars in Immunology (Elsevier). doi:10.1016/j.smim.2017.07.011

Desai, J., Deva, S., Lee, J. S., Lin, C. C., Yen, C. J., Chao, Y., et al. (2020). Phase IA/IB Study of Single-Agent Tislelizumab, an Investigational Anti-PD-1 Antibody, in Solid Tumors. J. Immunother. Cancer 8 (1). doi:10.1136/jitc-2019-000453

Diefenbach, A., Jensen, E. R., Jamieson, A. M., and Raulet, D. H. (2001). Rael and H60 Ligands of the NKG2D Receptor Stimulate Tumour Immunity. Nature 413 (6852), 165-171. doi:10.1038/35093109

Du, Y., and Wei, Y. (2019). Therapeutic Potential of Natural Killer Cells in Gastric Cancer. Front. Immunol. 9, 3095. doi:10.3389/fimmu.2018.03095

Edge, S. B., Byrd, D. R., Carducci, M. A., Compton, C. C., Fritz, A., and Greene, F. (2010). AJCC Cancer Staging Manual. New York: Springer.

Engel, J. B., Honig, A., Kapp, M., Hahne, J. C., Meyer, S. R., Dietl, J., et al. (2014). Mechanisms of Tumor Immune Escape in Triple-Negative Breast Cancers (TNBC) with and without Mutated BRCA 1. Arch. Gynecol. Obstet. 289 (1), 141-147. doi:10.1007/s00404-013-2922-9

Enzinger, P. C., and Mayer, R. J. (2003). Esophageal Cancer. N. Engl. J. Med. 349 (23), 2241-2252. doi:10.1056/NEJMra035010

Feng, D., Peng, C., Li, C., Zhou, Y., Li, M., Ling, B., et al. (2009). Identification and Characterization of Cancer Stem-like Cells from Primary Carcinoma of the Cervix Uteri. Oncol. Rep. 22 (5), 1129-1134. doi:10.3892/or_00000545

Fife, B. T., and Pauken, K. E. (2011). The Role of the PD-1 Pathway in Autoimmunity and Peripheral Tolerance. Ann. N. Y Acad. Sci. 1217 (1), 45-59. doi:10.1111/j.1749-6632.2010.05919.x

Francisco, L. M., Sage, P. T., and Sharpe, A. H. (2010). The PD-1 Pathway in Tolerance and Autoimmunity. Immunol. Rev. 236 (1), 219-242. doi:10.1111/ j.1600-065X.2010.00923.x

Groh, V., Bahram, S., Bauer, S., Herman, A., Beauchamp, M., and Spies, T. (1996). Cell Stress-Regulated Human Major Histocompatibility Complex Class I Gene Expressed in Gastrointestinal Epithelium. Proc. Natl. Acad. Sci. U S A. 93 (22), 12445-12450. doi:10.1073/pnas.93.22.12445

Havel, J. J., Chowell, D., and Chan, T. A. (2019). The Evolving Landscape of Biomarkers for Checkpoint Inhibitor Immunotherapy. Nat. Rev. Cancer 19 (3), 133-150. doi:10.1038/s41568-019-0116-x

Herbst, R. S., Soria, J. C., Kowanetz, M., Fine, G. D., Hamid, O., Gordon, M. S., et al. (2014). Predictive Correlates of Response to the Anti-PD-L1 Antibody MPDL3280A in Cancer Patients. Nature 515 (7528), 563-567. doi:10.1038/ nature 14011

Huang, B. Y., Zhan, Y. P., Zong, W. J., Yu, C. J., Li, J. F., Qu, Y. M., et al. (2015). The PD-1/b7-H1 Pathway Modulates the Natural Killer Cells versus Mouse Glioma Stem Cells. PloS one 10 (8), e0134715. doi:10.1371/journal.pone.0134715

Igarashi, T., Wynberg, J., Srinivasan, R., Becknell, B., McCoy, J. P., Jr, Takahashi, Y., et al. (2004). Enhanced Cytotoxicity of Allogeneic NK Cells with Killer Immunoglobulin-like Receptor Ligand Incompatibility against Melanoma and Renal Cell Carcinoma Cells. Blood 104 (1), 170-177. doi:10.1182/blood2003-12-4438

Ingram, Z., Madan, S., Merchant, J., Carter, Z., Gordon, Z., Carey, G., et al. (2021). Targeting Natural Killer T Cells in Solid Malignancies. Cells 10 (6), 1329. doi:10.3390/cells10061329 
Janjigian, Y. Y., Bendell, J., Calvo, E., Kim, J. W., Ascierto, P. A., Sharma, P., et al. (2018). CheckMate-032 Study: Efficacy and Safety of Nivolumab and Nivolumab Plus Ipilimumab in Patients with Metastatic Esophagogastric Cancer. J. Clin. Oncol. 36 (28), 2836-2844. doi:10.1200/JCO.2017.76.6212

Jung, H. I., Jeong, D., Ji, S., Ahn, T. S., Bae, S. H., Chin, S., et al. (2017). Overexpression of PD-L1 and PD-L2 Is Associated with Poor Prognosis in Patients with Hepatocellular Carcinoma. Cancer Res. Treat. 49 (1), 246-254. doi:10.4143/crt.2016.066

Jung, I. H., Kim, D. H., Yoo, D. K., Baek, S. Y., Jeong, S. H., Jung, D. E., et al. (2018). In Vivo study of Natural Killer (NK) Cell Cytotoxicity against Cholangiocarcinoma in a Nude Mouse Model. In Vivo 32 (4), 771-781. doi:10.21873/invivo.11307

Jung, J. (2014). Human Tumor Xenograft Models for Preclinical Assessment of Anticancer Drug Development. Toxicol. Res. 30 (1), 1-5. doi:10.5487/ TR.2014.30.1.001

Kang, Y. K., Boku, N., Satoh, T., Ryu, M. H., Chao, Y., Kato, K., et al. (2017). Nivolumab in Patients with Advanced Gastric or Gastro-Oesophageal junction Cancer Refractory to, or Intolerant of, at Least Two Previous Chemotherapy Regimens (ONO-4538-12, ATTRACTION-2): a Randomised, Double-Blind, Placebo-Controlled, Phase 3 Trial. Lancet 390 (10111), 2461-2471. doi:10.1016/ S0140-6736(17)31827-5

Keir, M. E., Butte, M. J., Freeman, G. J., and Sharpe, A. H. (2008). PD-1 and its Ligands in Tolerance and Immunity. Annu. Rev. Immunol. 26, 677-704. doi:10.1146/annurev.immunol.26.021607.090331

Kim, S.-W., Roh, J., and Park, C.-S. (2016). Immunohistochemistry For Pathologists: Protocols, Pitfalls, And Tips. J. Pathol. Transl. Med. 50 (6), 411.

Kitano, A., Ono, M., Yoshida, M., Noguchi, E., Shimomura, A., Shimoi, T., et al. (2017). Tumour-infiltrating Lymphocytes Are Correlated with Higher Expression Levels of PD-1 and PD-L1 in Early Breast Cancer. ESMO open 2 (2), e000150. doi:10.1136/esmoopen-2016-000150

Kokowski, K., Stangl, S., Seier, S., Hildebrandt, M., Vaupel, P., and Multhoff, G. (2019). Radiochemotherapy Combined with NK Cell Transfer Followed by Second-Line PD-1 Inhibition in a Patient with NSCLC Stage IIIb Inducing Long-Term Tumor Control: a Case Study. Strahlenther Onkol 195 (4), 352-361. doi:10.1007/s00066-019-01434-9

Lanuza, P. M., Pesini, C., Arias, M. A., Calvo, C., Ramirez-Labrada, A., and Pardo, J. (2020). Recalling the Biological Significance of Immune Checkpoints on NK Cells: a Chance to Overcome LAG3, PD1, and CTLA4 Inhibitory Pathways by Adoptive NK Cell Transfer?. Front. Immunol. 10, 3010. doi:10.3389/ fimmu.2019.03010

Lesokhin, A. M., Callahan, M. K., Postow, M. A., and Wolchok, J. D. (2015). On Being Less Tolerant: Enhanced Cancer Immunosurveillance Enabled by Targeting Checkpoints and Agonists of T Cell Activation. Sci. Transl Med. 7 (280), 280sr1-281sr. doi:10.1126/scitranslmed.3010274

Li, J., Chen, L., Xiong, Y., Zheng, X., Xie, Q., Zhou, Q., et al. (2017). Knockdown of PD-L1 in Human Gastric Cancer Cells Inhibits Tumor Progression and Improves the Cytotoxic Sensitivity to CIK Therapy. Cell Physiol Biochem 41 (3), 907-920. doi:10.1159/000460504

Li, T., Zhang, Q., Jiang, Y., Yu, J., Hu, Y., Mou, T., et al. (2016). Gastric Cancer Cells Inhibit Natural Killer Cell Proliferation and Induce Apoptosis via Prostaglandin E2. Oncoimmunology 5 (2), e1069936. doi:10.1080/2162402X.2015.1069936

Li, X., Shao, C., Shi, Y., and Han, W. (2018). Lessons Learned from the Blockade of Immune Checkpoints in Cancer Immunotherapy. J. Hematol. Oncol. 11 (1), 31-26. doi:10.1186/s13045-018-0578-4

Liu, Y., Cheng, Y., Xu, Y., Wang, Z., Du, X., Li, C., et al. (2017). Increased Expression of Programmed Cell Death Protein 1 on NK Cells Inhibits NK-CellMediated Anti-tumor Function and Indicates Poor Prognosis in Digestive Cancers. Oncogene 36 (44), 6143-6153. doi:10.1038/onc.2017.209

Liu, Y., Wei, G., Cheng, W. A., Dong, Z., Sun, H., Lee, V. Y., et al. (2018). Targeting Myeloid-Derived Suppressor Cells for Cancer Immunotherapy. Cancer Immunol. Immunotherimmunotherapy 67 (8), 1181-1195. doi:10.1007/ s00262-018-2175-3

Ljunggren, H. G., and Malmberg, K. J. (2007). Prospects for the Use of NK Cells in Immunotherapy of Human Cancer. Nat. Rev. Immunol. 7 (5), 329-339. doi:10.1038/nri2073

Malmberg, K.-J., Carlsten, M., Björklund, A., Sohlberg, E., Bryceson, Y. T., and Ljunggren, H.-G. (2017). "Natural Killer Cell-Mediated Immunosurveillance of Human Cancer," in Seminars in Immunology (Elsevier). doi:10.1016/ j.smim.2017.08.002
Marçais, A., Viel, S., Grau, M., Henry, T., Marvel, J., and Walzer, T. (2013). Regulation of Mouse NK Cell Development and Function by Cytokines. Front. Immunol. 4, 450. doi:10.3389/fimmu.2013.00450

Melaiu, O., Lucarini, V., Cifaldi, L., and Fruci, D. (2020). Influence of the Tumor Microenvironment on NK Cell Function in Solid Tumors. Front. Immunol. 10, 3038. doi:10.3389/fimmu.2019.03038

Meuten, D., Moore, F., and George, J. (2016). Mitotic Count and the Field of View Area: Time to Standardize. Los Angeles, CA: SAGE Publications Sage CA.

Meza-Junco, J., Au, H. J., and Sawyer, M. B. (2011). Critical Appraisal of Trastuzumab in Treatment of Advanced Stomach Cancer. Cancer Manag. Res. 3, 57-64. doi:10.2147/CMR.S12698

Mlecnik, B., Bindea, G., Angell, H. K., Maby, P., Angelova, M., Tougeron, D., et al. (2016). Integrative Analyses of Colorectal Cancer Show Immunoscore Is a Stronger Predictor of Patient Survival Than Microsatellite Instability. Immunity 44 (3), 698-711. doi:10.1016/j.immuni.2016.02.025

Nair, A. B., and Jacob, S. (2016). A Simple Practice Guide for Dose Conversion between Animals and Human. J. Basic Clin. Pharm. 7 (2), 27-31. doi:10.4103/ 0976-0105.177703

Nishimura, H., and Honjo, T. (2001). PD-1: an Inhibitory Immunoreceptor Involved in Peripheral Tolerance. Trends Immunol. 22 (5), 265-268. doi:10.1016/s1471-4906(01)01888-9

Overman, M. J., McDermott, R., Leach, J. L., Lonardi, S., Lenz, H. J., Morse, M. A., et al. (2017). Nivolumab in Patients with Metastatic DNA Mismatch RepairDeficient or Microsatellite Instability-High Colorectal Cancer (CheckMate 142): an Open-Label, Multicentre, Phase 2 Study. Lancet Oncol. 18 (9), 1182-1191. doi:10.1016/S1470-2045(17)30422-9

Oyer, J. L., Gitto, S. B., Altomare, D. A., and Copik, A. J. (2018). PD-L1 Blockade Enhances Anti-tumor Efficacy of NK Cells. Oncoimmunology 7 (11), e1509819. doi:10.1080/2162402X.2018.1509819

Parvin, T., Das, C., Choudhury, M., Chattopadhyay, B. K., and Mukhopadhyay, M. (2019). Prognostic Utility of Cyclin D1 In Invasive Breast Carcinoma. Indian J. Surg. Oncol. 10 (1), 167-173.

Patel, S. A., and Minn, A. J. (2018). Combination Cancer Therapy with Immune Checkpoint Blockade: Mechanisms and Strategies. Immunity 48 (3), 417-433. doi:10.1016/j.immuni.2018.03.007

Pedroza-Pacheco, I., Shah, D., Domogala, A., Luevano, M., Blundell, M., Jackson, N., et al. (2016). Regulatory T Cells Inhibit CD34+ Cell Differentiation into NK Cells by Blocking Their Proliferation. Sci. Rep. 6 (1), 1-13. doi:10.1038/ srep22097

Peng, L. S., Zhang, J. Y., Teng, Y. S., Zhao, Y. L., Wang, T. T., Mao, F. Y., et al. (2017). Tumor-Associated Monocytes/Macrophages Impair NK-Cell Function via TGF $\beta 1$ in Human Gastric Cancer. Cancer Immunol. Res. 5 (3), 248-256. doi:10.1158/2326-6066.CIR-16-0152

Pietra, G., Manzini, C., Rivara, S., Vitale, M., Cantoni, C., Petretto, A., et al. (2012). Melanoma Cells Inhibit Natural Killer Cell Function by Modulating the Expression of Activating Receptors and Cytolytic Activity. Cancer Res. 72 (6), 1407-1415. doi:10.1158/0008-5472.CAN-11-2544

Raneros, A. B., Minguela, A., Rodriguez, R. M., Colado, E., Bernal, T., Anguita, E., et al. (2017). Increasing TIMP3 Expression by Hypomethylating Agents Diminishes Soluble MICA, MICB and ULBP2 Shedding in Acute Myeloid Leukemia, Facilitating NK CellMediated Immune Recognition. Oncotarget 8 (19), 31959-31976. doi:10.18632/oncotarget.16657

Reagan-Shaw, S., Nihal, M., and Ahmad, N. (2008). Dose Translation from Animal to Human Studies Revisited. FASEB J. 22 (3), 659-661. doi:10.2217/ 14750708.5.5.659

Rezvani, K., Daher, M., Basar, R., Gokdemir, E., Baran, N., Uprety, N., et al. (2020). CIS Checkpoint Deletion Enhances the Fitness of Cord Blood Derived Natural Killer Cells Transduced with a Chimeric Antigen Receptor. New York: bioRxiv.

Shafi, S., Vantourout, P., Wallace, G., Antoun, A., Vaughan, R., Stanford, M., et al. (2011). An NKG2D-Mediated Human Lymphoid Stress Surveillance Response with High Interindividual Variation. Sci. Transl Med. 3 (113), 113 ra124. doi:10.1126/scitranslmed.3002922

Shevtsov, M., Pitkin, E., Ischenko, A., Stangl, S., Khachatryan, W., Galibin, O., et al. (2019). Ex Vivo Hsp70-activated NK Cells in Combination with PD-1 Inhibition Significantly Increase Overall Survival in Preclinical Models of Glioblastoma and Lung Cancer. Front. Immunol. 10, 454. doi:10.3389/ fimmu.2019.00454 
Shultz, L. D., Lyons, B. L., Burzenski, L. M., Gott, B., Chen, X., Chaleff, S., et al. (2005). Human Lymphoid and Myeloid Cell Development in NOD/LtSz-scid IL2R Gamma Null Mice Engrafted with Mobilized Human Hemopoietic Stem Cells. J. Immunol. 174 (10), 6477-6489. doi:10.4049/jimmunol.174.10.6477

Tahara, M., Muro, K., Hasegawa, Y., Chung, H. C., Lin, C. C., Keam, B., et al. (2018). Pembrolizumab in Asia-Pacific Patients with Advanced Head and Neck Squamous Cell Carcinoma: Analyses from KEYNOTE-012. Cancer Sci. 109 (3), 771-776. doi:10.1111/cas.13480

Terme, M., Ullrich, E., Aymeric, L., Meinhardt, K., Desbois, M., Delahaye, N., et al. (2011). IL-18 Induces PD-1-dependent Immunosuppression in Cancer. Cancer Res. 71 (16), 5393-5399. doi:10.1158/0008-5472.CAN-11-0993

Thrift, A. P., and El-Serag, H. B. (2020). Burden of Gastric Cancer. Clin. Gastroenterol. Hepatol. 18 (3), 534-542. doi:10.1016/j.cgh.2019.07.045

Topalian, S. L., Drake, C. G., and Pardoll, D. M. (2012). Targeting the PD-1/b7H1(pd-L1) Pathway to Activate Anti-tumor Immunity. Curr. Opin. Immunol. 24 (2), 207-212. doi:10.1016/j.coi.2011.12.009

Tsukihara, H., Nakagawa, F., Sakamoto, K., Ishida, K., Tanaka, N., Okabe, H., et al. (2015). Efficacy of Combination Chemotherapy Using a Novel Oral Chemotherapeutic Agent, TAS-102, Together with Bevacizumab, Cetuximab, or Panitumumab on Human Colorectal Cancer Xenografts. Oncol. Rep. 33 (5), 2135-2142. doi:10.3892/or.2015.3876

Uong, T. N. T., Lee, K. H., Ahn, S. J., Kim, K. W., Min, J. J., Hyun, H., et al. (2018). Realtime Tracking of Ex Vivo-expanded Natural Killer Cells toward Human TripleNegative Breast Cancers. Front. Immunol. 9, 825. doi:10.3389/fimmu.2018.00825

van Erp, E., van Kampen, M., van Kasteren, P., and de Wit, J. (2019). Viral Infection of Human Natural Killer Cells. Viruses 11 (3), 243. doi:10.3390/v11030243

Wadhwa, R., Taketa, T., Sudo, K., Blum, M. A., and Ajani, J. A. (2013). Modern Oncological Approaches to Gastric Adenocarcinoma. Gastroenterol. Clin. North. Am. 42 (2), 359-369. doi:10.1016/j.gtc.2013.01.011
Wu, Y., Cao, D., Qu, L., Cao, X., Jia, Z., Zhao, T., et al. (2017). PD-1 and PD-L1 Coexpression Predicts Favorable Prognosis in Gastric Cancer. Oncotarget 8 (38), 64066-64082. doi:10.18632/oncotarget.19318

Yin, M., Di, G., and Bian, M. (2018). Dysfunction of Natural Killer Cells Mediated by PD-1 and Tim-3 Pathway in Anaplastic Thyroid Cancer. Int. Immunopharmacol 64, 333-339. doi:10.1016/j.intimp.2018.09.016

Zhang, D., Jiang, F., Zaynagetdinov, R., Huang, H., Sood, V. D., Wang, H., et al. (2020). Identification and Characterization of M6903, an Antagonistic AntiTIM-3 Monoclonal Antibody. Oncoimmunology 9 (1), 1744921. doi:10.1080/ 2162402X.2020.1744921

Conflict of Interest: The authors declare that the research was conducted in the absence of any commercial or financial relationships that could be construed as a potential conflict of interest.

Publisher's Note: All claims expressed in this article are solely those of the authors and do not necessarily represent those of their affiliated organizations, or those of the publisher, the editors and the reviewers. Any product that may be evaluated in this article, or claim that may be made by its manufacturer, is not guaranteed or endorsed by the publisher.

Copyright (C) 2021 Abdolahi, Ghazvinian, Muhammadnejad, Ahmadvand, Aghdaei, Ebrahimi-Barough, Ai, Zali, Verdi and Baghaei. This is an open-access article distributed under the terms of the Creative Commons Attribution License (CC BY). The use, distribution or reproduction in other forums is permitted, provided the original author(s) and the copyright owner(s) are credited and that the original publication in this journal is cited, in accordance with accepted academic practice. No use, distribution or reproduction is permitted which does not comply with these terms. 